\title{
EFFECT OF MANDIBULAR SET-BACK SURGERY VERSUS BIMAXILLARY ORTHOGNATHIC SURGERY ON PHARYNGEAL AIRWAY SPACE AND CONSEQUENT DAYTIME SLEEPINESS IN DENTO-SKELETAL CLASS III MALOCCLUSION PATIENTS
}

\author{
Hussein Hatem*, Sameh A. Seif*, Walaa AbdElAty Ahmed** and Shaimaa Mohsen Refahee ${ }^{* * *}$
}

\begin{abstract}
Purpose: Pharyngeal airway space (PAS) assessment after orthognathic surgery is crucial due to the possible resultant breathing hazards. This study compared PAS after mandibular set-back surgery and bimaxillary surgery and its consequent effect on the patients' daytime sleepiness in class III dento-skeletal patients.
\end{abstract}

Patients and methods Twenty-four patients with dento-skeletal class III deformity were divided equally into two groups; group A underwent mandibular set-back surgery while group B had bimaxillary orthognathic surgery through mandibular set-back and maxillary advancement surgeries. PAS area was measured on lateral cephalometric radiographs. Daytime sleepiness was assessed by Epworth sleepiness scale (ESS). All results were recorded pre-surgically, immediate post-surgically and at 6-months post-surgically.

Results In group A patients, the PAS value at T0 (mean of $546.72 \pm 66.61 \mathrm{~mm} 2$ ) revealed a non-significant decrease after mandibular set-back surgery at T1 to reach a mean of $542.89 \pm 68.65$ $\mathrm{mm} 2$, which appeared to minimally relapse at T2 to a value still less than T0 $(544.00 \pm 68.62 \mathrm{~mm} 2)$ with a final decreased PAS value. In group B patients, the PAS value (mean of $555.05 \pm 75.04 \mathrm{~mm} 2$ ) revealed a non-significant increase after bimaxillary surgery at T1 reaching a mean of $555.73 \pm 79.34$ $\mathrm{mm} 2$ which re-increased at $\mathrm{T} 2$ to a mean value of $557.79 \pm 78.23 \mathrm{~mm} 2$. Following the pattern of PAS, the ESS recorded non-significant changes in both groups from the preoperative values to values at $\mathrm{T} 1$ and $\mathrm{T} 2$.

Conclusion Despite of the resulted post-surgical different changes, orthognathic surgery appeared to have no significant effect on PAS area nor on daytime sleepiness in a six-month duration.

KEYWORDS: Orthognathic surgery, Pharyngeal airway space, skeletal class III patients, Epworth sleepiness scale, daytime sleep level.

* Associate Professor of Oral and Maxillofacial Surgery, Oral and Maxillofacial Surgery Department, Faculty of Dentistry, Cairo University.

** Lecturer of Oral and Maxillofacial Radiology, Oral and Maxillofacial Radiology Department, Faculty of Dentistry, Cairo University

*** Lecturer of Oral and Maxillofacial Surgery, Oral and Maxillofacial Surgery Department, Faculty of Dentistry, Fayoum University. 


\section{INTRODUCTION}

Changes of the jaws' positions after different orthognathic surgery logically affect the pharyngeal airway space (PAS), since the jaws act as insertion points for the pharyngeal muscles and the surrounding tissues ${ }^{(1)}$. Additionally, PAS has a strong muscular envelope and a close relationship with the surrounding structures namely, the soft palate, epiglottis, tongue, and hyoid bone which tend to change after orthognathic surgery ${ }^{(2-4)}$.

Depending on the extent of skeletal defect, dentoskeletal class III patients needed 1-jaw surgery in the form of mandibular set-back (MS), or 2-jaw in the form of MS and maxillary advancement (MA) orthognathic surgeries as a treatment ${ }^{(5-6)}$.

Some studies declared that single-jaw surgery, which moves the mandible slightly backward, along with the muscles and other soft tissue attachments, affected the PAS and positioning of the tongue due to the slight backward rotation of the angle of mandible and cervical spine with reference to the skull base and hyoid bone ${ }^{(7-8)}$.

Accordingly, authors speculated the advantageous 2-jaw surgeries over single-jaw surgeries on PAS affection, due to the reduced amount of mandibular set-back which is usually compensated by the concomitant maxillary advancement resulting in less posterior tongue movement and less sealing of the oropharynx. Additionally, they expected a resultant superseding stability after the associated smaller jaw movements in sagittal dimensions ${ }^{(9-10)}$.

In the literature, no agreement appeared to be on the effect of different orthognathic surgeries on PAS changes. Mehra et al (11) and Liukkonen et al ${ }^{(12)}$ stated that corrections of the maxillo-mandibular deformities may lead a decreased PAS in cases of mandibular setback. However, Kawakami et al ${ }^{(13)}$ asserted that mandibular setback has no significant effect on PAS. Then again, the null hypothesis in the literature stated that orthognathic surgery would not change the PAS dimensions ${ }^{(14)}$.

Nevertheless, some studies acknowledged that post-surgical reduction in PAS leads to a decrease in pharyngeal pressure and breathing difficulty specially during sleep. The main issue in the resulted sleep apnea is the periodic airway obstruction and sleep disturbance accompanied with multiple daytime sleep. Accordingly, pharyngeal airway reduction after mandibular setback surgery remains vital when planning jaws' surgeries mainly in dento-skeletal class III patients to prevent possible resultant airway hazards ${ }^{(15-16)}$.

Considering the above, this study aimed to assess the changes in the PAS after the one-jaw mandibular set-back surgery and the two-jaw bimaxillary orthognathic surgery and its consequent effect on daytime sleepiness.

\section{PATIENTS AND METHODS}

The trail was designed as prospective clinical trial. A power analysis was designed to have adequate power to apply a two-sided statistical test of the null hypothesis that there is no difference between pre and post treatment pharyngeal airway area. By adopting an alpha and beta levels of (0.05) (i.e. power $=95 \%)$ and an effect size (d) of (1.32) calculated, based on the results of Agarwal (17), the predicted sample size (n) was a total of (20) cases. Sample size was increased by (20\%) to account for possible dropouts to be (24) cases. Sample size calculation was performed using G-Power version 3.1.9.7.

The present study was performed in the department of oral and maxillofacial surgery, faculty of Dentistry, Cairo University. The ethical approval was obtained from Cairo University institution and written consents were acquired from all patients after explanation of the procedure steps and complications. The trial was recorded on ClinicalTrial.gov (ClinicalTrials.gov identifier: NCT04629859) 


\section{Preoperative preparation and Patient grouping}

This study included twenty-four medically stable patients suffering from dento-skeletal class III malocclusion. Study model analysis, cephalometric assessment, and orthodontic treatment were performed for all the patients preoperatively. Patients with uncontrolled systemic diseases, craniofacial syndromes, bone anomalies, and sleepbreathing disorders were excluded. All surgeries were performed by the same surgical team.

The selected patients were divided equally into two groups, 12 patients each; Group A patients underwent mandibular set-back surgery in the form of bilateral sagittal split osteotomy (BSSO) surgery, while group B patients had Bimaxillary orthognathic surgery in the form of le fort I maxillary advancement with mandibular set-back BSSO surgery utilizing typical documented methodology ${ }^{(18,19)}$. (Fig. 1-2).

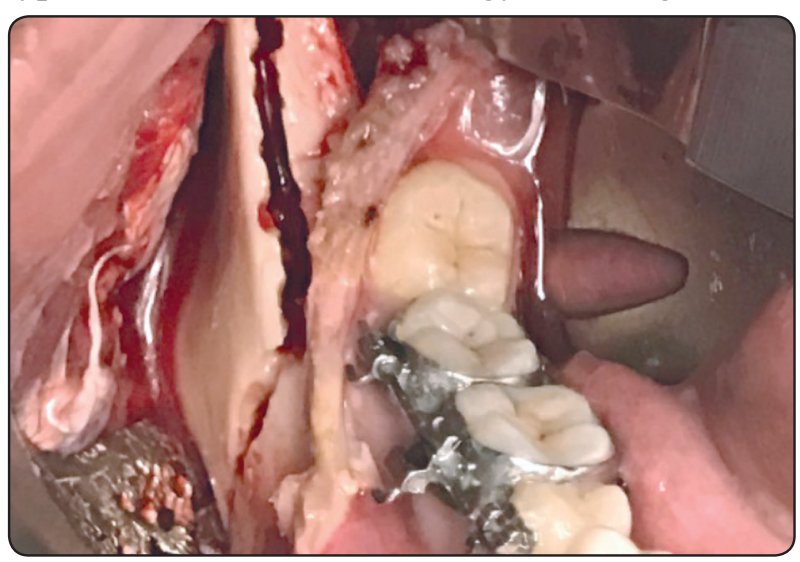

Fig. (1): A photograph showing mandibular set-back cuts.

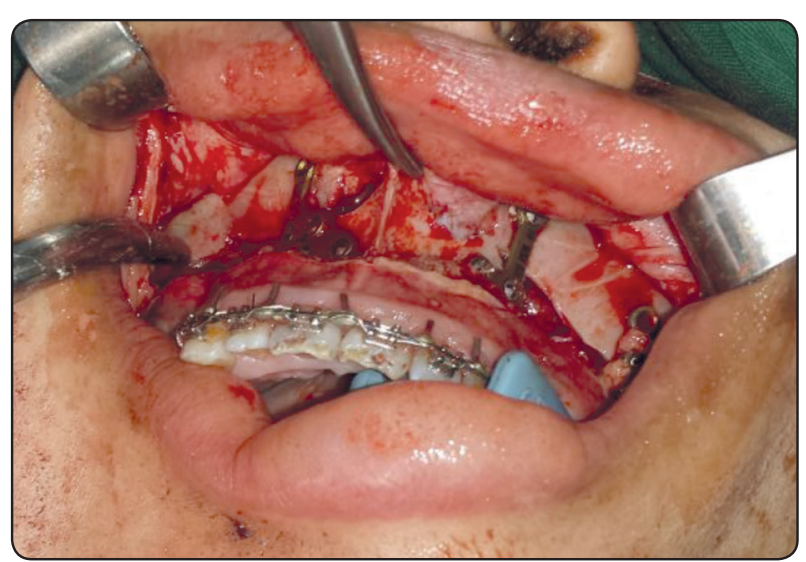

Fig. (2): A photograph showing maxillary advancement cuts and fixation.
All patients were followed-up for a period of six months to record any postoperative complications, and their clinical and esthetic content.

\section{Pharyngeal airway surface area and Cephalo- metric analysis}

To measure surgical changes and the PAS, the cephalometric radiograph of each patient in the maximum inter-cuspal position was taken at a magnification ratio of $1: 1$ before surgery (T0), immediately after surgery (T1) and at 6-months post-surgery as a follow-up. Cephalometric analysis was conducted using the superimposition technique.

Cephalometric analyses were performed through the superimposition technique of the pre-surgical, post-surgical and follow up images. The integrated reference points were the nasion $(\mathrm{N})$, sella $(\mathrm{S})$, and basion (B). A horizontal line corresponding to the Frankfurt horizontal plane (passing through the inferior borders of the bony orbits and the upper margin of the auditory meatus) and a vertical line perpendicular to the Frankfurt horizontal plane through the sella point was used. As delineated by the authors in several procedures ${ }^{(2,20)}$, the pharyngeal airway is demarcated inferiorly by a line passing through the tip of epiglottis and the superior tip of the hyoid bone, namely Line A, while the reteoglossal and the retro-palatal airway is separated by a line extending from the basion parallel to line A.

All the reference points and lines were conveyed to the images taken at T1 and T2. The PAS was measured twice by the same assessor at different times for each follow-up visit. The average values were recorded and compared.

\section{Daytime sleepiness level and Epworth sleepiness score (ESS)}

Daytime sleepiness level was assessed for all patients in each group by self-administrated questionnaire based on ESS ${ }^{(16,21)}$. It consisted of a 4-point scale (0-3) with a total score of 0 to 24 . The collected data at $\mathrm{T} 0, \mathrm{~T} 1$, and $\mathrm{T} 2$ were documented and statistically compared. 


\section{Statistical analysis}

Numerical data were represented as mean and standard deviation (SD) values. The normality was tested by Shapiro-Wilk's test while homogeneity of variances was tested using Levene's test. Mauchly's test was used to check the Sphericity assumption. For PAS area, inter and intragroup comparisons were analyzed using independent t-test and repeated measures ANOVA, respectively. While for Epworth score, inter and intragroup comparisons were analyzed using Mann Whitney U and Freidman's tests. A value of $p \leq 0.05$ was considered the significance level within all tests. Statistical analysis was performed with R-statistical analysis software version 4.0.3 for Windows.

\section{RESULTS}

Twenty-four patients suffering from Dentoskeletal class III malocclusion were included in this study, distributed equally into Group A patients who underwent mandibular set-back surgery in the form of BSSO surgery, and group B patients who had Bimaxillary orthognathic surgery in the form of maxillary advancement with mandibular set-back surgery. They were 16 females and 8 males with a mean age of 21.3 years at the surgery time.

No unexpected events were reported after surgeries of both groups. All patients were clinically content. The mean mandibular set-back distance in group A was $5.4 \mathrm{~mm}$, while in group B had a maxillary advancement mean of $3.4 \mathrm{~mm}$ and mandibular set-back mean of $4.2 \mathrm{~mm}$.

\section{Group A Mandibular set-back follow-up}

The preoperative total PAS value at $\mathrm{T} 0$ recorded a mean of $546.72 \mathrm{~mm}^{2}$ which revealed a nonsignificant decrease at $\mathrm{T} 1$ to a mean value of 542.89 $\mathrm{mm}^{2}$. This appeared to re-increase after 6 months at T2 to a mean value of $544.00 \mathrm{~mm}^{2}$ which was still less than T0. (Fig. 3)

Similarly, the ESS records non-significantly changed from the preoperative value of 6.25 to a post-surgical T1 value of 6.67 and a decreased T2 value of 6.17 . (Table 1)

\section{Group B Bimaxillary surgery follow-up:}

The total preoperative mean PAS value at T0 was $555.0 .5 \mathrm{~mm}^{2}$ revealed a non-significant increase post-surgically at $\mathrm{T} 1$ to a value of $555.73 \mathrm{~mm}^{2}$ which appeared to re-increase after 6 months post-surgically at T2 to a mean value of $557.79 \mathrm{~mm}^{2}$. (Fig. 4)

Regarding the ESS values, a non-significant change from 6.42 preoperatively to 6.92 at $\mathrm{T} 1$ and 6.93 at T2. (Table 1)

By statistical comparison over the 6-months study period, LCR analysis of the total non-segmented PAS and the ESS values in both techniques showed non-significant intra-group changes in different follow-up intervals. ( $p>0.05$ ) (Table 2-3) (Fig. 5-6)

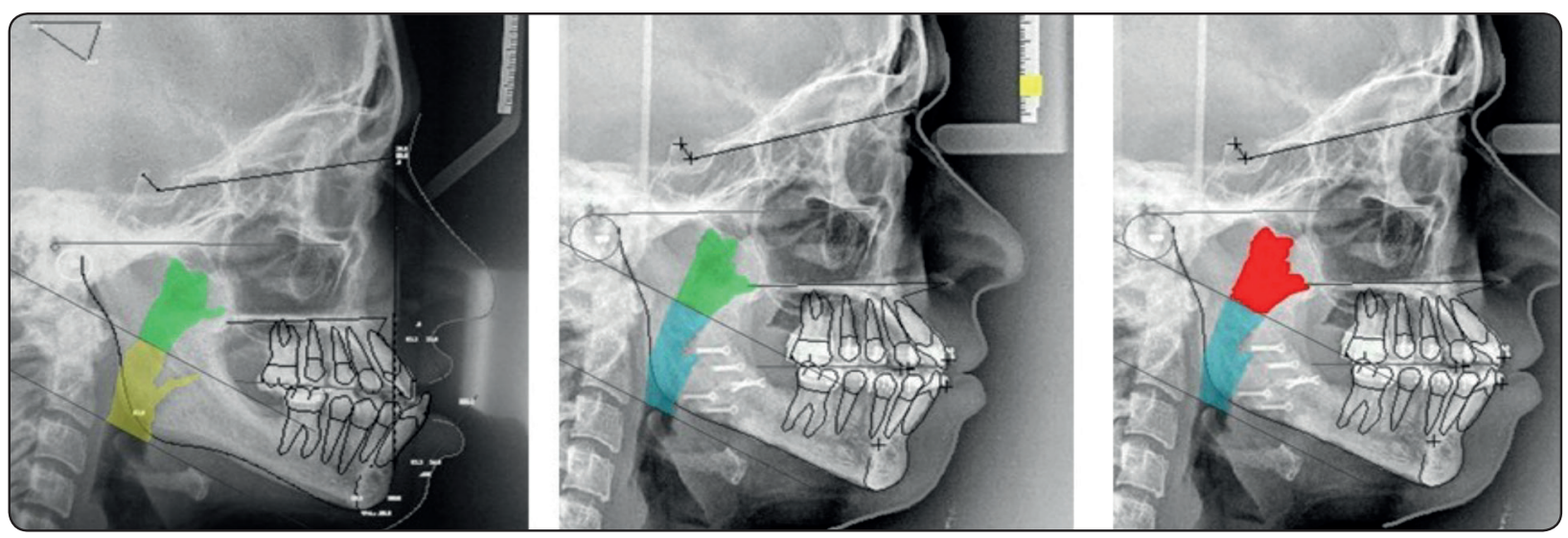

Fig. (3): Lateral cephalometric images showing pre-surgical PAS measurement at T0, T1 an T2 respectively in group A. 


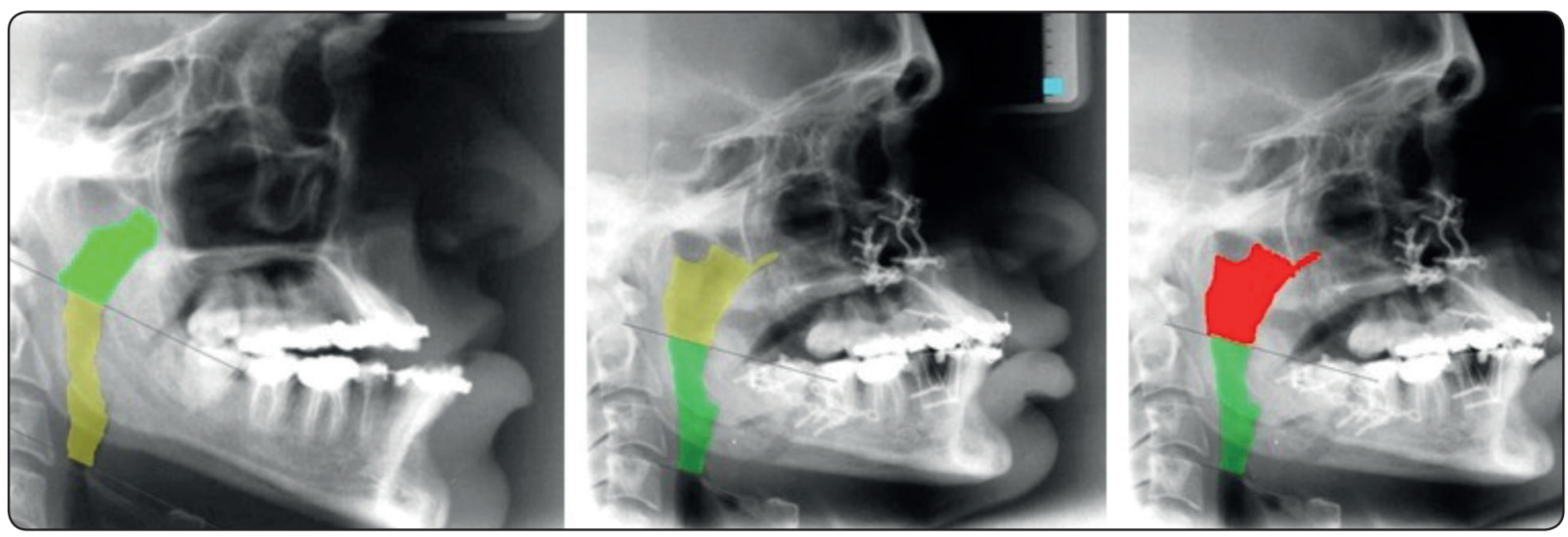

Fig. (4) Lateral cephalometric images showing pre-surgical PAS measurement at T0, T1 an T2 respectively in group B.

TABLE (1): Descriptive statistics of PAS and ESS records.

\begin{tabular}{|c|c|c|c|c|c|c|c|c|}
\hline \multirow{2}{*}{ Measurement } & \multirow{2}{*}{ Time } & \multirow{2}{*}{ Material } & \multirow{2}{*}{ Mean } & \multicolumn{2}{|c|}{$95 \% C I$} & \multirow{2}{*}{$S D$} & \multirow{2}{*}{ Median } & \multirow{2}{*}{$I Q R$} \\
\hline & & & & Lower & Upper & & & \\
\hline \multirow{6}{*}{$\begin{array}{l}\text { Pharyngeal } \\
\text { airway } \\
\text { surface area } \\
\quad\left(\mathrm{mm}^{2}\right)\end{array}$} & \multirow{2}{*}{$\begin{array}{c}\text { Pre- } \\
\text { operative }\end{array}$} & $\begin{array}{c}\text { Mandibular } \\
\text { setback }\end{array}$ & 546.72 & 509.03 & 584.41 & 66.61 & 534.66 & 97.89 \\
\hline & & $\begin{array}{c}\text { Bimaxillary } \\
\text { surgery }\end{array}$ & 555.05 & 512.59 & 597.50 & 75.04 & 558.12 & 141.86 \\
\hline & \multirow{2}{*}{ T1 } & $\begin{array}{c}\text { Mandibular } \\
\text { setback }\end{array}$ & 542.89 & 504.05 & 581.73 & 68.65 & 531.50 & 115.74 \\
\hline & & $\begin{array}{c}\text { Bimaxillary } \\
\text { surgery }\end{array}$ & 555.73 & 510.84 & 600.62 & 79.34 & 553.82 & 148.00 \\
\hline & \multirow{2}{*}{$\mathbf{T} 2$} & $\begin{array}{c}\text { Mandibular } \\
\text { setback }\end{array}$ & 544.00 & 505.17 & 582.82 & 68.62 & 532.19 & 115.98 \\
\hline & & $\begin{array}{c}\text { Bimaxillary } \\
\text { surgery }\end{array}$ & 557.79 & 513.53 & 602.05 & 78.23 & 554.85 & 147.45 \\
\hline \multirow{6}{*}{$\begin{array}{c}\text { Epworth } \\
\text { score }\end{array}$} & \multirow{2}{*}{$\begin{array}{c}\text { Pre- } \\
\text { operative }\end{array}$} & $\begin{array}{c}\text { Mandibular } \\
\text { setback }\end{array}$ & 6.25 & 5.70 & 6.80 & 0.97 & 6.00 & 1.25 \\
\hline & & $\begin{array}{c}\text { Bimaxillary } \\
\text { surgery }\end{array}$ & 6.42 & 5.85 & 6.98 & 1.00 & 6.00 & 1.00 \\
\hline & \multirow{2}{*}{ T1 } & $\begin{array}{c}\text { Mandibular } \\
\text { setback }\end{array}$ & 6.67 & 6.39 & 6.95 & 0.49 & 7.00 & 1.00 \\
\hline & & $\begin{array}{c}\text { Bimaxillary } \\
\text { surgery }\end{array}$ & 6.92 & 6.54 & 7.29 & 0.67 & 7.00 & 0.25 \\
\hline & \multirow{2}{*}{$\mathbf{T} 2$} & $\begin{array}{c}\text { Mandibular } \\
\text { setback }\end{array}$ & 6.17 & 5.49 & 6.84 & 1.19 & 6.50 & 2.00 \\
\hline & & $\begin{array}{c}\text { Bimaxillary } \\
\text { surgery }\end{array}$ & 6.93 & 6.25 & 7.42 & 1.03 & 7.00 & 2.00 \\
\hline
\end{tabular}

$95 \% C I=95 \%$ confidence interval for the mean; $S D=$ standard deviation; $I Q R=$ interquartile range 
TABLE (2): Inter and intragroup comparisons for PAS area

\begin{tabular}{|c|c|c|c|c|}
\hline \multirow{2}{*}{ Time } & \multicolumn{2}{|c|}{ Pharyngeal airway surface area $($ Mean $\pm S D)$} & \multirow{2}{*}{ Statistic } & \multirow{2}{*}{$p$-value } \\
\hline & Mandibular setback & Bimaxillary surgery & & \\
\hline Pre-operative $\left(\mathrm{mm}^{2}\right)$ & $546.72 \pm 66.61^{\mathrm{A}}$ & $555.05 \pm 75.04^{\mathrm{A}}$ & 0.287 & $0.777 n s$ \\
\hline$T 1\left(\mathrm{~mm}^{2}\right)$ & $542.89 \pm 68.65^{\mathrm{A}}$ & $555.73 \pm 79.34^{\mathrm{A}}$ & 0.424 & $0.676 \mathrm{~ns}$ \\
\hline$T 2\left(\mathrm{~mm}^{2}\right)$ & $544.00 \pm 68.62^{\mathrm{A}}$ & $557.79 \pm 78.23^{\mathrm{A}}$ & 0.459 & $0.651 n s$ \\
\hline Pre-operative-T1 (\%) & $0.95 \pm 1.13$ & $1.53 \pm 2.53$ & 0.726 & $0.479 \mathrm{~ns}$ \\
\hline$T 1-T 2(\%)$ & $0.21 \pm 0.08$ & $0.41 \pm 0.70$ & 1.011 & $0.333 n s$ \\
\hline Pre-operative-T2 (\%) & $0.79 \pm 1.13$ & $1.44 \pm 2.69$ & 0.777 & $0.449 \mathrm{~ns}$ \\
\hline
\end{tabular}

Means with different superscript letters in the same vertical column are statistically significant different; *significant $(p<0.05)$

TABLE (3): Inter and intragroup comparisons for ESS

\begin{tabular}{|c|c|c|c|c|}
\hline \multirow{2}{*}{ Time } & \multicolumn{2}{|c|}{ Epworth score $($ Mean $\pm S D)$} & \multirow{2}{*}{ Statistic } & \multirow{2}{*}{$p$-value } \\
\hline & Mandibular setback & Bimaxillary surgery & & \\
\hline Pre-operative & $6.25 \pm 0.97^{\mathrm{A}}$ & $6.42 \pm 1.00^{\mathrm{A}}$ & 76.500 & $0.740 \mathrm{~ns}$ \\
\hline$T 1$ & $6.67 \pm 0.49^{\mathrm{A}}$ & $6.92 \pm 0.67^{\mathrm{A}}$ & 82.000 & $0.362 \mathrm{~ns}$ \\
\hline$T 2$ & $6.17 \pm 1.19^{\mathrm{A}}$ & $6.83 \pm 1.03^{\mathrm{A}}$ & 94.000 & $0.199 n s$ \\
\hline Pre-operative-T1 (\%) & $13.07 \pm 11.85$ & $12.11 \pm 7.97$ & -0.233 & $0.818 \mathrm{~ns}$ \\
\hline$T 1-T 2(\%)$ & $10.32 \pm 12.11$ & $14.10 \pm 7.90$ & 0.906 & $0.376 \mathrm{~ns}$ \\
\hline Pre-operative-T2 (\%) & $8.78 \pm 14.95$ & $12.38 \pm 14.47$ & 0.600 & $0.555 \mathrm{~ns}$ \\
\hline
\end{tabular}

Means with different superscript letters in the same vertical column are statistically significant different; ns; not significant $(p<0.05)$

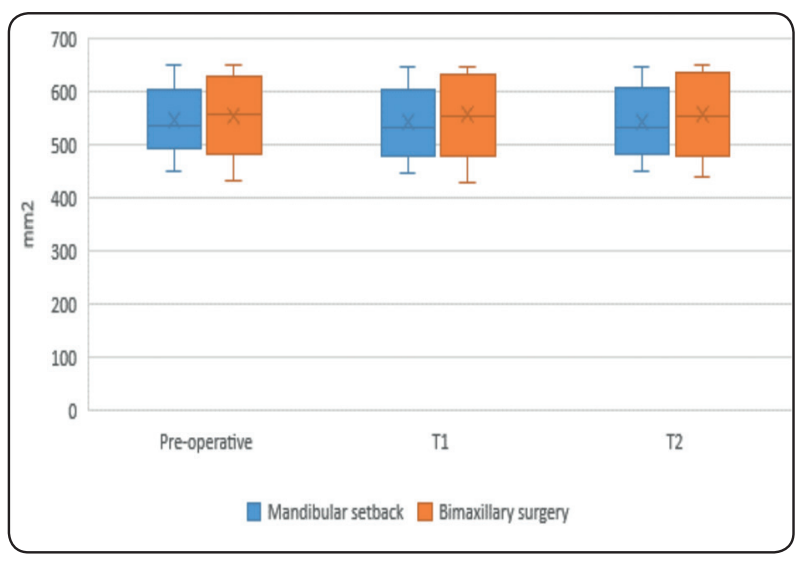

Fig. (5): Box plot showing PAS area (mm2)

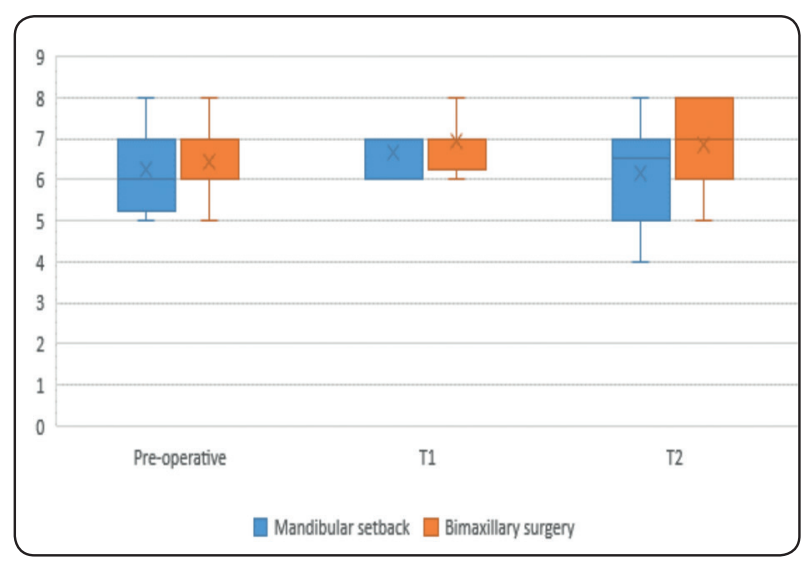

Fig. (6): Box plot showing ESS 


\section{DISCUSSION}

Patients with class III dento-skelatal deformity are generally treated either by MS (1-jaw surgery) or bimaxillary surgery (2-jaws surgery). The postsurgical resultant change in the bony relations in turn affect the surrounding structures, including PAS, with different values depending on the primary surgical bony alterations. Thus, a detailed analysis of airway changes before orthognathic surgery is crucial due to the possible post-surgical clinical consequences of pharyngeal narrowing and collapse with the resultant airway hazards ${ }^{(1,15)}$.

Though PAS is a three dimensional volumetric structure which supposed to require an analysis in the three planes using an 3D-imaging technique, namely CBCT or CT, Kim et al ${ }^{(22)}$ and Sutthiprapaporn et $\boldsymbol{a l}^{(23)}$ affirmed the various deceiving pitfalls of the complex analysis in the 3D-CBCT and CT along with their high radiation exposure drawback. Moreover, Kochel and Meyer ${ }^{(24)}$ correlated strongly between the accuracy of the 2D-LCR and that of the 3D-CBCT in spaces interpretation.

Therefore, despite the debate in the literature, LCR remains the most suitable, with least radiation exposure, easy and inexpensive standard method for skeletal and soft tissue and PAS evaluation (25,26). Accordingly, in this study, LCR has been implemented in delineating PAS as a $2 \mathrm{D}$ area calculated via superimposition of standardized bony and soft tissue landmarks.

In the literature, PAS area definition by borders is inconsistent making it difficult to compare the outcome of different studies ${ }^{(27,28)}$, hence the standardized protocol utilized by a single radiologist in PAS analysis in this study, employing Gurani et $\boldsymbol{a l}{ }^{(2)}$ proposed landmarks in other measurements, producing the length and width of the PAS which consisted mainly of the retro-glossal and the retropalatal regions.

In contrast to the hypothesis in the literature which states that a skeletal change of $2 \mathrm{~mm}$ or more should supposedly arise a significant soft tissue dimensional change ${ }^{(29,30)}$, in group A patients, PAS area reported a final insignificant decrease in the area measured on LCR at T2 after 6 months follow-up. This decrease was logically attributed to the posteriorly moved mandibular landmarks with the concomitant backward displacement of the soft tissue attachments and retro-glossal space reduction.

While in group $B$ patients, an insignificant increase in PAS area was radiographically recorded post-surgically at T1 and after 6 months' follow-up at T2. This was due to the less decrease in retroglossal space than that of group $A$ due to the less surgical mandibular set back distance compensated by the accompanied maxillary advancement which produced an additional increase in the retro-palatal space, absent in group A patients.

In this study, the changes in PAS area values in each group were insignificant in both post-surgical readings; T1 and T2. According to Lee and Hwang $^{(20)}$, and Jackobsone et al ${ }^{(31)}$, this was attributed to the limited expansile ability of the surrounding pharyngeal complex soft tissue layers and thick muscles.

In contrast to Gurani et al (2) who had stable results for 2 years, in this study, the results of T2 revealed a slight increase in both groups. This change over time was attributed in other studies to the inter-individual adaptive ability of the complex soft tissue, fascia, and the two layer muscles of the pharynx ${ }^{(1,3,29,32)}$.

Worth mentioning, the needed mandibular setback distance in group A (mean of $4.4 \mathrm{~mm}$ ) was more than that of group B (mean of $3.2 \mathrm{~mm}$ ) due to the nature of the employed surgery in the second group with the compensatory maxillary advancement. This explained the reported controversial changes in PAS between studies in the literature which had segmented the total airway space into several compartments ${ }^{(33,34)}$.

While the patient's head posture, respiration and epiglottis might relatively affect the PAS analysis 
on LCR, post-surgical minor rotation of the jaw along with the easily influenced position of the hyoid bone and its attachments after surgery had a direct relation on PAS records ${ }^{(35-38)}$. Moreover, Kim et al ${ }^{(39)}$ declared the gender significance in airway volume appearing as a decrease in females more than males which was not applicable in this study due to the dominant female inclusion in the included sample. Additionally, according to $\boldsymbol{E} \boldsymbol{l}$ and Palamo ${ }^{(40)}$, weight gain through pharyngeal fatty tissue proliferation change PAS values over time. Thus, these several reported factors appeared to be non-solvable as study variables due to their nonreproducible feature which may affect directly the measurement accuracy and the instability of the PAS results after surgery.

Therefore, this different methodological study designs and lack of standardization together with the various surgical and radiographic procedures and personal variations implemented in the soft tissue adaptation phenomenon, tended to convey no predictable outcome after orthognathic surgery regarding PAS area.

In another perspective, daytime sleepiness during different activities is primarily affected by night sleep disturbance problems and the concomitant sleep apnea. The main issue associated with sleep apnea is snoring due to the partial airway obstruction and the consequent oxygen deprivation and its effects ${ }^{(41)}$.

Various methods can be used to assess the sleep disturbances including the polysomnography and the Epworth sleepiness score (ESS). In this study, similar to Rosenthal and Dolan ${ }^{(16)}$, the simpler selfadministrated ESS was preferred and used, while, the polysomnography was prohibited for its expensive, complex, and non- easily available features.

For additional evidence of our results, ESS for both groups followed the PAS deviations' pattern and recorded similar non-significant alterations after surgery at $\mathrm{T} 1$ and $\mathrm{T} 2$ records. This was attributed to the recorded insignificant PAS changes previously discussed, which had minimal effect on airway obstruction and the consequent sleep apnea and daytime sleepiness.

Therefore, despite of the resulted post-surgical decrease and increase in PAS after one-jaw mandibular setback and two-jaw bimaxillary surgery respectively, orthognathic surgery in management of dento-skeletal class III patients appeared to have no major or significant effect on pharyngeal airway space nor on daytime sleepiness in a six-month duration.

\section{Recommendations}

To address the shortcomings of this study and similar studies, we recommend a longer term followup studies with special attention to standardize head positioning and PAS segmentation in measurement.

\section{Declaration of conflicting interests}

The authors declare that there is no conflict of interest.

\section{Funding resources}

This research received no specific grant from any funding agency in the public, commercial, or non-profit sectors.

\section{REFERENCES}

1. Tan SK, Tang A, Leung WK and Zwahlen RA: ThreeDimensional Pharyngeal Airway Changes after 2-Jaw Orthognathic Surgery with Segmentation in Dento-Skeletal Class III Patients. J Craniofac Surg; 30: 1533-1538, 2019.

2. Gurani SF, Di Carlo G, Thorn JJ, Ingerslev J, Cattaneo PM, and Pinholt EM: Two-Year Postoperative Upper Airway Cone-Beam Computed Tomographic Outcomes Based on a Verified Upper Airway Analysis Following Bimaxillary Orthognathic Surgery. J Oral Maxillofac Surg 77:1435$1445,2019$.

3. Shin JH, Kim MA, Park IY, Park YH: A 2-year followup of changes after bimaxillary surgery in patients with mandibular prognanthism: 3-Dimensional analysis of pharyngeal airway volume and hyoid bone position. J Oral Maxillofac Surg 73:340, 2015. 
4. Lee J-Y, Kim Y-I, Hwang D-S, Park S-B: Effect of maxillary setback movement on upper airway in patients with Class III skeletal deformities. J Craniofac Surg 24:387, 2013.

5. Santagata M,Tozzi U,Lamart E, et al. Effect of orthognathic surgery on the posterior airway space in patients affected by skeletal Class III malocclusion. J Maxillofac Oral Surg; 14: 682-686, 2015.

6. Hong JS, Park YH, Kim YJ, et al. Three-dimensional changes in pharyngeal airway in skeletal class III patients undergoing orthognathic surgery. J Oral Maxillofac Surg; 69: e401-e408, 2011.

7. He L, He S, Wu X, and Huang Y: Three-Dimensional Morphological Changes of the Upper Airway in Patients with Skeletal Class III Malocclusion after Orthognathic Surgery. J Craniofac Surg; 30: 2451-2455, 2019.

8. Gu G, Nagata J, Suto M, et al. Hyoid position, pharyngeal airway and head posture in relation to relapse after the mandibular setback in skeletal Class III. Clin Orthod Res; 3:67-77, 2000 .

9. Tan SK, Leung WK, Tang ATH, et al. Effects of mandibular setback with or without maxillary advancement osteotomies on pharyngeal airways: an overview of systematic reviews. PLoS One; 12: e0185951, 2017.

10. Yang Y, Yang K, Zhao Y. Three-dimensional changes in the upper airway of skeletal class iii patients after different orthognathic surgical procedures. J Oral Maxillofac Surg; 76: 155-164, 2018.

11. Mehra P, Downe M, Pitta MC, Wolford LM: Pharyngeal airway space changes after counterclockwise rotation of the maxillomandibular complex. Am J Orthod Dentofacial Orthop 120: 154, 2001.

12. Liukkonen M, Vahatalo K, Peltomaki T, Tiekso J, Happonen RP: Effect of mandibular setback surgery on the posterior airway size. Int J Adult Orthod Orthognath Surg 17: 41, 2002.

13. Kawakami M, Yamamoto K, Fujomoti M, Ohgi K, Inoue M, Kirita T: Changes in tongue and hyoid positions, and posterior airway space following mandibular setback surgery. J Craniomaxillofac Surg 33: 107, 2005.

14. Bin LR, Filho LI, Yamashita AL, De Souza GN, Pinto NS, Mendese RA, Ramos AL, Previdelli ITS and Iwaki $\mathrm{CV}$ : How does bimaxillary orthognathic surgery change dimensions of maxillary sinuses and pharyngeal airway space? Angle Orthod. 0000; 00: 000-000.
15. Shah DH, Kim KB, McQuilling MW, et al. Computational fluid dynamics for the assessment of upper airway changes in skeletal Class III patients treated with mandibular setback surgery. Angle Orthod; 86: 976-982, 2016.

16. Rosenthal L and Dolan D. The Epworth Sleepiness Scale in the Identification of Obstructive Sleep Apnea. J Nerv Ment Dis;196: 429-431, 2008.

17. Agarwal, S. S. Evaluation of Pharyngeal Airway Dimensions Following Mandibular Setback Surgery in Patients Treated with Surgery First Orthognathic Approach. J Sleep Disord Ther; 302: 2167-77, 2019.

18. Buchanan EP, Hyman CH. Le Fort I osteotomy. Semin plast surg; 27(3):149-154, 2013.

19. cherackal GJ, Thomas E, Prathap A. combined orthodontic and surgical approach in the correction of a class III skeletal malocclusion with mandibular prognanthism and vertical maxillary excess using bimaxillary osteotomy. J case reports in dentistry; 1:12, 2013.

20. Lee $\mathrm{K}$ and Hwang SJ: Change of the upper airway after mandibular setback surgery in patients with mandibular prognathism and anterior open bite. J Maxillofacial Plastic and Reconstructive Surgery 2019: 41(1):1-8.

21. Johns MW. Daytime sleepiness, snoring, and obstructive apnea: The Epworth sleepiness scale. Chest;103(1): 30-36, 1993.

22. Kim M-A, Kim B-R, Youn J-K, Kim Y-JR, Park Y-H: Head posture and pharyngeal airway volume changes after bimaxillary surgery for mandibular prognathism. J Cranio Maxillofac Surg; 42:531-535, 2014.

23. Sutthiprapaporn P, Tanimoto K, Ohtsuka M, Nagasaki T, Iida Y, Katsumata A. Positional changes of oropharyngeal structures due to gravity in the upright and supine positions Dento Maxillo Fac Radiol; 37: 130-135, 2008.

24. Kochel J, Meyer-Marcotty P. Short-term pharyngeal airway changes after mandibular advancement surgery in adult class-II patients: A three-dimensional retrospective study. J Orofac Orthop; 74(2): 137-152, 2013.

25. Mah J, Hatcher D. Three-dimensional craniofacial imaging. Am J Orthod Dentofacial Orthop 2004:126(3): 308-309.

26. Visser H, Rodig T, Hermann KP. Dose reduction by direct-digital cephalometric radiography. Angle Orthod 2001:71(3): 159-163. 
27. Christovam IO, Lisboa CO, Ferreira DMTP, et al: Upper airway dimensions in patients undergoing orthognathic surgery: A systematic review and meta-analysis. Int J Oral Maxillofac Surg 2016:45(4):460-471.

28. Rosario HD, Oliveira GMS, Freires IA, et al. Efficiency of bimaxillary advancement surgery in increasing the volume of the upper airways: A systematic review of observational studies and meta-analysis. Eur Arch Oto rhino laryngol 2017: 274(1):35-44.

29. Joss CU, Joss-Vassalli IM, Kiliaridis S, Kuijpers-Jagtmann AM: Soft tissue profile changes after bilateral sagittal split osteotomy for mandibular setback: a systematic review. J Oral Maxillofac Surg 2010: 68: 1260-1269.

30. Dolce C, Hatch JP, Van Sickels JE, Rugh JD: Rigid versus wire fixation for mandibular advancement: skeletal and dental changes after 5 years. Am J Orthod Dento facial Orthop 2002:121: 610-619.

31. Jakobsone G, Neimane L, Krumina G: Two- and threedimensional evaluation of the upper airway after bimaxillary correction of Class III malocclusion. Oral Surg Oral Med Oral Pathol Oral Radiol Endod 2010:110:234-242.

32. Sahoo NK, Jayan B, Ramakrishna N, Chopra SS, Kochar G: Evaluation of upper airway dimensional changes and hyoid position following mandibular advancement in patients with skeletal class II malocclusion. J Craniofac Surg 2012:23: 623-627.

33. Souza Pinto GN, Iwaki Filho L, Previdelli ITDS, et al: Three dimensional alterations in pharyngeal airspace, soft palate, and hyoid bone of Class II and Class III patients submitted to bimaxillary orthognathic surgery: a retrospective study. J Cranio maxillofac Surg 2019: 47(6):883-894.

34. Yamashita AL, Iwaki Filho L, Leite PCC, et al. Three dimensional analysis of the pharyngeal airway space and hyoid bone position after orthognathic surgery. J Craniomaxillofac Surg. 2017: 45: 1408-1414.

35. Fernandez-Ferrer L, Montiel-Company JM, Pinho T, et al. Effects of mandibular setback surgery on upper airway dimensions and their influence on obstructive sleep apnea-A systematic review. Craniomaxillofac Surg 2015: 43(2):248-253.

36. Gurani SF, Di Carlo G, Cattaneo PM, et al: Effect of head and tongue posture on the pharyngeal airway dimensions and morphology in three-dimensional imaging: A systematic review. J Oral Maxillofac Res 2016: 7(1)1.

37. Li YM, Liu JL, Zhao JL, et al. Morphological changes in the pharyngeal airway of female skeletal class III patients following bimaxillary surgery: a cone beam computed tomography evaluation. Int J Oral Maxillofac Surg 2014: 43:862-867.

38. Tepecik T, Ertas U, Akgun M. Effects of bimaxillary orthognathic surgery on pharyngeal airway and respiratory function at sleep in patients with class III skeletal relationship. J Craniomaxillofac Surg 2018:46: 645-653.

39. Kim HS, Kim GT, Kim S, et al. Three-dimensional evaluation of the pharyngeal airway using cone-beam computed tomography following bimaxillary orthognathic surgery in skeletal class III patients. Clin Oral Investig 2016: 20: 915-922.

40. El H, Palomo JM: Airway volume for different dentofacial skeletal patterns. Am J Orthod Dentofacial Orthop 2008: 139: 511-521.

41. Shahar E, Whitney CW, Redline S, Lee ET, Newman AB, Javier Nieto F, O'Connor GT, Boland LL, Schwartz JE, Samet JM. Sleep-disordered breathing and cardiovascular disease: Cross-sectional results of the sleep heart health study. Am J Respir Crit Care Med. 2001; 163:19-25. 